\title{
Individual and combined effects of anovulation and cytological endometritis on the reproductive performance of dairy cows
}

\author{
A. Vieira-Neto, ${ }^{\star}$ R. O. Gilbert, † W. R. Butler,ł J. E. P. Santos,§ E. S. Ribeiro,§ M. M. Vercouteren,\# \\ R. G. Bruno, $\|^{1}$ J. H. J. Bittar, $\mid$ and K. N. Galvãoף ${ }^{* * 2}$ \\ *Departamento de Medicina Veterinária, Universidade do Estado de Santa Catarina, Lages, SC 88520, Brazil \\ †Department of Clinical Sciences, and \\ ‡Department of Animal Science, Cornell University, Ithaca, NY 14853 \\ $\S$ Department of Animal Sciences, University of Florida, Gainesville 32610 \\ \#Department of Farm Animal Health, Utrecht University, 3508 TD Utrecht, the Netherlands \\ IISchool of Veterinary Medicine, University of California-Davis, Tulare 93274 \\ IDepartment of Large Animal Clinical Sciences, College of Veterinary Medicine, University of Florida, Gainesville 32610 \\ ${ }^{* \star}$ D. H. Barron Reproductive and Perinatal Biology Research Program, University of Florida, Gainesville 32610
}

\section{ABSTRACT}

The objective was to evaluate the individual and combined effect of anovulation and cytological endometritis (CTE) on the reproductive performance of dairy cows. A total of 1,569 cows from 3 data sets were used. In data set 1, 403 Holstein cows from 5 dairies in New York were used. In data set 2, 750 Holstein cows from 2 dairies, one in Florida and one in California were used. In data set 3, 416 dairy cows, 165 Holsteins, 36 Jerseys, and 215 Holstein-Jersey crossbreeds from a grazing dairy in Florida were used. Cyclicity and CTE was determined at $35 \pm 3$ (data set 2) or $49 \pm 3 \mathrm{~d}$ in milk (data sets 1 and 3). A variable (VarCycCTE) containing all 4 possible permutations between cyclicity (cyclic $=$ Cyc; anovular $=$ Anov) and CTE (present = CTE; absent $=$ Healthy) was created. In the combined data set (sets 1,2, and 3), pregnancy per artificial insemination $(\mathrm{P} / \mathrm{AI})$ diagnosed at 30 to $38 \mathrm{~d}$ after first $\mathrm{AI}$ was affected by VarCycCTE, with AnovCTE cows having decreased P/AI compared with CycHealthy cows (21.3 vs. $46.7 \%)$, whereas AnovHealthy $(37.9 \%)$ and CycCTE cows $(36.0 \%)$ had intermediate $\mathrm{P} / \mathrm{AI}$. Pregnancy per artificial insemination for the individual data sets and for pregnancy diagnosed at 63 to $74 \mathrm{~d}$ after artificial insemination followed a similar pattern. Pregnancy loss was not affected by VarCycCTE. Hazard of pregnancy up to $300 \mathrm{~d}$ in milk was affected by VarCycCTE in the combined data sets 1 and 2, with AnovCTE [hazard ratio $(\mathrm{HR})=0.55]$, AnovHealthy cows $(\mathrm{HR}=0.71)$, and CycCTE $(\mathrm{HR}=0.8)$ having decreased hazard of pregnancy compared with CycHealthy cows. Median

\footnotetext{
Received November 16, 2013.

Accepted April 15, 2014.

${ }^{1}$ Current address: Zoetis, Fresno, CA 93705.

${ }^{2}$ Corresponding author: galvaok@ufl.edu
}

days open were 200, 159, 145, and 121 for AnovCTE, AnovHealthy, CycCTE, and CycHealthy, respectively. Hazard of pregnancy for the individual data sets followed a similar pattern. In summary, both anovulation and CTE were negatively associated with reproductive performance and, when combined, they had an additive negative effect.

Key words: cyclicity, cytological endometritis, reproductive performance, dairy cow

\section{INTRODUCTION}

Uterine diseases such as metritis and endometritis are highly prevalent in dairy cows (Sheldon et al., 2006). Cytological endometritis (CTE), which is characterized by increased PMNL migration into the uterine lumen (Kasimanickam et al., 2004; Gilbert et al., 2005), affects approximately $30 \%$ of lactating dairy cows, with the prevalence ranging from 5 to $>70 \%$ around 50 DIM (Gilbert et al., 2005; Cheong et al., 2011). Delayed ovarian cyclicity or anovulation is another common disorder of dairy cows, with more than $20 \%$ of the lactating dairy cows being affected around 60 DIM (Cerri et al. 2004; Walsh et al., 2007; Santos et al. 2009) and with some herds having more than $40 \%$ anovulatory cows around that time (El-Zarkouny et al. 2004; Chebel et al. 2006; Santos et al. 2009).

Several studies have shown that both anovulation (Darwash et al. 1997; Santos et al. 2009; Galvão et al., 2010b) and CTE (Gilbert et al., 2005; Galvão et al., 2009a; Dubuc et al., 2010) are negatively associated with reproductive performance; namely, decreased pregnancy per AI (P/AI), increased pregnancy loss (PL), and increased time to pregnancy (Santos et al., 2004; Gilbert et al., 2005; Lima et al., 2013). Nonetheless, anovulation is positively associated with CTE (Galvão et al., 2010b), which could make the individual association between each condition and reproductive 
performance spurious, as either condition could be confounding the effect of the other. Therefore, the objective of the current study was to evaluate the individual and combined effect of anovulation and CTE on the reproductive performance of dairy cows.

\section{MATERIALS AND METHODS}

\section{Experimental Design and Sample Size}

This was a retrospective cohort study. The data were conveniently sampled from previous studies that had collected similar information (Bruno et al., 2007; Galvão et al., 2009a; Bittar et al., 2013; Ribeiro et al., 2013). A total of 1,569 cows from 3 separate data sets were used. Because the data were sampled by convenience, no a priori calculation of sample size existed.

For clarity, data are presented below as 3 separate data sets based on differences and similarities regarding the use of timed AI programs as part of the herd reproductive management (yes or no), housing type (confinement or pasture), and timing of CTE evaluation $(35$ or $49 \pm 3$ DIM).

\section{Animals, Housing, and Feeding}

Data Set 1. A total of 403 Holstein cows (163 primiparous and 240 multiparous) from 5 commercial dairies located in upstate New York were used. Herd sizes ranged from 70 to 1,500 lactating cows, and the rolling herd average was approximately $11,500 \mathrm{~kg}$ of milk/cow per year. Cows were housed in freestall barns and milked 3 times per day. Cows were fed the same TMR within herd, formulated to meet or exceed the NRC (2001) nutrient requirements for lactating Holstein cows weighing $680 \mathrm{~kg}$ and producing $45 \mathrm{~kg}$ of $3.5 \%$ FCM. Cows from this data set were part of a previous study that evaluated the effect of $\mathrm{PGF}_{2 \alpha}$ on uterine health and fertility (Galvão et al., 2009a).

Data Set 2. A total of 750 Holstein cows (308 primiparous and 442 multiparous) from 2 commercial dairies located in Northern Florida $(\mathrm{n}=429)$ and central California $(\mathrm{n}=321)$ were used. In Florida, the herd size was approximately 500 lactating cows, cows were housed in freestall barns and milked twice daily, and the rolling herd average was approximately 10,500 $\mathrm{kg}$ of milk/cow per year. A portion of the cows $(\mathrm{n}=$ 245) from Florida were part of a previous study that evaluated the effect of GnRH administration early in lactation on uterine health and fertility (Bittar et al., 2013). In California, the herd size was approximately 1,500 lactating cows, cows were housed in dry lots and milked twice daily, and the rolling herd average was approximately $12,400 \mathrm{~kg}$ of milk/cow per year. Cows from
California were part of a previous study that evaluated the effect of uterine infusion with ceftiofur on uterine health and fertility (Bruno et al., 2007). Within herd, cows were fed the same TMR formulated to meet or exceed the NRC (2001) nutrient requirements for lactating Holstein cows weighing $680 \mathrm{~kg}$ and producing 45 $\mathrm{kg}$ of $3.5 \%$ FCM.

Data Set 3. A total of 416 multiparous cows (165 Holsteins, 36 Jerseys, and 215 Holstein-Jersey crossbreeds) from 1 commercial dairy located in north-central Florida were used. The herd size was approximately 1,200 lactating cows, the cows were housed on pasture and milked twice per day, and the rolling herd average was approximately $6,000 \mathrm{~kg}$ of milk/cow per year. Cows were maintained on irrigated pasture paddocks of 2.7 ha and managed in a daily rotational method, allowing a $15-\mathrm{d}$ resting period. Cows were offered 7 to $13 \mathrm{~kg}$ of concentrates/d on an as-fed basis (86 to $88 \%$ DM) during and immediately after each milking, according to forage availability, which was estimated at the entrance to each paddock using rising plate meters. Cows from this data set were part of a previous study that evaluated the prevalence of periparturient diseases and effects on fertility (Ribeiro et al., 2013).

\section{Evaluation of Cyclicity and CTE}

Data Set 1. Cyclicity was determined based on serum progesterone concentrations measured in samples collected at 21, 35, and $49 \pm 3$ DIM as previously reported (Galvão et al., 2009a). Cows were classified as cyclic if the progesterone concentration was $\geq 1 \mathrm{ng} / \mathrm{mL}$ in at least 1 measurement, and were classified as anovular if the progesterone concentration was $<1 \mathrm{ng} / \mathrm{mL}$ in all measurements. Uterine lavage was performed at $49 \pm 3$ DIM to diagnose CTE, as previously described (Gilbert et al., 2005; Galvão et al., 2009a). Briefly, the perineum of the cow was cleansed and a $62.5-\mathrm{cm}$ Flex Tip sterile plastic infusion pipette (Exodus Breeders Corp., York, PA) was manipulated through the cervix into the uterus; sterile saline solution $(20 \mathrm{~mL})$ was then injected into the uterus, agitated gently per rectum, and a sample of the fluid aspirated. The recovered fluid was centrifuged at $50 \times g$ for $3 \mathrm{~min}$ at room temperature using a cytocentrifuge (Cyto-Tek; Sakura Finetechnical Japan Co. Ltd., Tokyo, Japan) directly onto a glass slide. After drying, the slides were fixed and stained using a Romanowsky type stain and examined under $400 \times$ magnification. Cells were identified as PMNL, large mononuclear leukocytes, small mononuclear leukocytes, and uterine epithelial cells. At least 200 cells were counted and results expressed as percentage of PMNL. The threshold used for CTE diagnosis was $\geq 5 \%$ PMNL, as previously reported (Gilbert et al., 2005). 
Data Set 2. Cyclicity was determined based on the presence of a corpus luteum/corpora lutea (CL) detected by transrectal ultrasonography (Easy Scan; BCF Technology Ltd., Livingston, UK) performed at 21 and $35 \pm 3$ DIM. Cows were classified as cyclic if they had a CL $\geq 20 \mathrm{~mm}$ (McArt et al., 2010) in at least 1 ultrasound examination, and were classified as anovular if a CL was absent in both examinations. The diagnosis of CTE was performed at $35 \pm 3$ DIM by uterine cytology using the cytobrush technique (Kasimanickam et al., 2004) in Florida or uterine lavage, as described in data set 1 , in California. For the cytobrush technique, a Cytobrush Plus GT (CooperSurginal Inc., Trumbull, CT) was threaded onto a stainless-steel rod of a bovine uterine cytology gun (Aries Surgical, Davis, $\mathrm{CA}$ ), passed through the cervix into the base of the larger horn, where the stainless-steel tube was retracted to expose the cytobrush. Endometrial cytology samples were collected by rotating the cytobrush in a clockwise direction while in contact with the uterine wall. The cytobrush was retracted into the stainless-steel tube before removal from the uterus. The cytobrush was immediately smeared onto a glass slide, air dried, and stained within $6 \mathrm{~h}$, as described in data set 1 . Because the evaluation was performed earlier in lactation and to maintain consistency with the original studies (Bruno et al., 2007; Bittar et al., 2013), the threshold used to diagnose CTE was $\geq 10 \%$ PMNL, as previously described (Kasimanickam et al., 2004). It is worth noting that in the work by Kasimanickam et al. (2004), cows with clinical endometritis were excluded, which could potentially affect the optimal threshold. Nonetheless, others have found a similar threshold ( $\geq 9 \%$ PMNL) when cows with clinical endometritis were not excluded (Barlund et al., 2008). It is also worth noting that a threshold of $6 \%$ PMNL at $35 \pm 3$ DIM has been proposed (Galvão et al., 2009a; Dubuc et al., 2010).

Data Set 3. Cyclicity was determined based on the presence of a CL detected by transrectal ultrasonography as described for data set 2 , but performed at 35 and $49 \pm 3$ DIM. The diagnosis of CTE was performed at $49 \pm 3$ DIM as described for data set 1 ; therefore, the threshold used to diagnose CTE was $\geq 5 \%$ PMNL.

\section{Evaluation of BCS and Calving Season}

Body condition score was evaluated at $35 \pm 3$ DIM in all cows from all data sets using a 5 -point scale $(1=$ emaciated; $5=$ obese) as previously reported (Ferguson et al., 1994). Calving season [winter (December, January, and February), spring (March, April, and May), summer (June, July, and August), and fall (September, October, and November)] was recorded for all cows in all data sets.

\section{Reproductive Management}

Data Set 1. The reproductive management varied among farms; however, the AI program was based on estrous detection and the voluntary waiting period was set to 49 DIM. No timed-AI program was used. All cows were examined for pregnancy by palpation per rectum at $38 \pm 3 \mathrm{~d}$ after AI. Data on pregnancy confirmation was not available for this data set.

Data Set 2. All cows were presynchronized with 2 injections of $\mathrm{PGF}_{2 \alpha} 14 \mathrm{~d}$ apart at 37 and $51 \pm 3$ DIM (California) or 41 and $55 \pm 3$ DIM (Florida), which was followed 12 (Florida) or 14 (California) d later by the Ovsynch-56 timed-AI protocol (GnRH injection, $\mathrm{PGF}_{2 \alpha}$ injection $7 \mathrm{~d}$ later, $\mathrm{GnRH}$ injection $56 \mathrm{~h}$ later, and then AI 16 to $20 \mathrm{~h}$ later); therefore, the timed AI was performed at $75 \pm 3$ (California) or $77 \pm 3$ (Florida) DIM. In California, cows were artificially inseminated based on detected estrus after the second $\mathrm{PGF}_{2 \alpha}$ injection of the presynchronization protocol. Estrous detection was not performed in Florida. Pregnancy diagnosis was performed by transrectal ultrasonography at $32 \mathrm{~d}$ after AI in Florida, and by palpation per rectum at $38 \pm 3$ $\mathrm{d}$ after AI in California. Nonpregnant cows were resynchronized using the Ovsynch-56 timed-AI program immediately after nonpregnancy diagnosis. Confirmation of pregnancy was performed at $70 \pm 5 \mathrm{~d}$ after AI by palpation per rectum in both dairies.

Data Set 3. All cows were AI after presynchronization with 2 injections of $\mathrm{PGF}_{2 \alpha} 14 \mathrm{~d}$ apart, which was followed $10 \mathrm{~d}$ later by the 5-d Co-Synch timed-AI program according to a preplanned breeding season from January to March of 2010. On average, first AI was performed at 86 DIM. Pregnancy diagnosis was performed by transrectal ultrasonography at $30 \mathrm{~d}$ after $\mathrm{AI}$, and pregnancy confirmation was performed at $65 \mathrm{~d}$ after AI by palpation per rectum.

Across data sets, the first pregnancy diagnosis (PD1) was performed between 30 and $41 \mathrm{~d}$ after AI and the confirmation pregnancy diagnosis (PD2) was performed between 65 and $75 \mathrm{~d}$ after AI.

\section{Statistical Analysis}

Binary outcomes such as P/AI and PL were analyzed by logistic regression with fixed and random effects models using PROC GLIMMIX of SAS (version 9.3; SAS Institute Inc., Cary, NC). A backward elimination was performed by removing explanatory variables from the model with $P>0.10$ according to the Wald statistics criterion. To evaluate the individual and combined effects of anovulation and CTE, a new variable (VarCycCTE) containing all 4 possible permutations between cyclicity $($ cyclic $=\mathbf{C y c}$; anovular $=$ Anov $)$ 
and CTE (present $=$ CTE; absent $=$ Healthy) was created. First, the effect of VarCycCTE was evaluated in each data set separately and then in a combined data set containing available data from all data sets. Models included the fixed effects of VarCycCTE, calving season (winter, spring, summer, and fall), parity (primiparous or multiparous), BCS at 35 DIM $(\leq 2.75$ or $>2.75$ ), and the respective treatment applied as part of the original study, and herd as a random variable when data originated from more than 1 herd. In data set 3, it was not possible to evaluate PL using PROC GLIMMIX because 1 group did not have any PL, leading to quasi-complete separation of data points and unreliable estimates. Therefore, PL in data set 3 was analyzed by the Fisher exact test using PROC FREQ of SAS.

Hazard of pregnancy up to 300 DIM was analyzed by the Cox proportional hazard model using PROC PHREG of SAS with the same explanatory variables as described above; however, herd was included as strata if more than 1 herd was included in the analysis. The variable time was the interval in days from calving to pregnancy. Cows sold or dead, or those that did not conceive by 300 DIM were censored. For the analysis of time to pregnancy, cows were considered pregnant if they were diagnosed pregnant at PD1 (data set 1) or PD2 (data sets 2 and 3). Kaplan-Meier plots and median days to pregnancy up to 300 DIM were generated using MedCalc version 12.7 for Windows software (MedCalc Software, Mariakerke, Belgium). Statistical significance was considered at $P \leq 0.05$ and a tendency toward statistical significance was considered at $0.05<$ $P \leq 0.10$.

\section{RESULTS}

Pregnancy per AI at PD1 is shown in Table 1 for the separate data sets and in Table 2 for the combined data set. In data set 1, no main effect of VarCycCTE
$(P=0.63)$ existed. In data set 2, an effect $(P=0.03)$ of VarCycCTE was detected, with cows that were anovular and had CTE (AnovCTE) having decreased P/ $\mathrm{AI}$ at PD1 compared with cows that were cyclic and had a healthy uterus (CycHealthy; 22.2 vs. $42.3 \% ; P$ $=0.003)$, whereas cows that were anovular and had a healthy uterus (AnovHealthy; $38.9 \% ; P=0.78$ ) and cows that were cyclic but had CTE (CycCTE; 38.5\%; $P$ $=0.45$ ) had intermediate P/AI. In data set 3 (grazing herd), an effect $(P=0.03)$ of VarCycCTE was also detected. Similarly, AnovCTE cows had decreased P/ $\mathrm{AI}$ at PD1 compared with CycHealthy cows (12.5 vs. $60.6 \% ; P=0.03$ ), whereas AnovHealthy $(46.1 \% ; P$ $=0.09$ ) and CycCTE (48.9\%; $P=0.13$ ) cows were intermediate and only approached significance. In the combined data set (data sets 1,2, and 3), an effect of VarCycCTE $(P<0.001)$ existed, with results following a similar pattern to the individual data sets. The AnovCTE cows had decreased P/AI at PD1 compared with CycHealthy cows $(21.3$ vs. $46.7 \% ; P<0.001)$, whereas AnovHealthy $(37.9 \% ; P=0.14)$ and CycCTE cows $(36.0 \% ; P=0.06)$ were intermediate and only approached significance.

Pregnancies per AI at PD2 for the separate data sets (data sets 2 and 3 only) and for the combined data set are shown in Table 3 . In data set 2 , an effect $(P=0.01)$ of VarCycCTE was detected, with AnovCTE cows having decreased P/AI at PD2 compared with CycHealthy cows (19.4 vs. $38.9 \% ; P=0.001)$, whereas AnovHealthy $(32.7 \% ; P=0.30)$ and CycCTE $(33.3 \% ; P=0.21)$ had intermediate $\mathrm{P} / \mathrm{AI}$. In data set 3 , which was conducted in a grazing herd, a tendency existed for an effect $(P=0.06)$ of VarCycCTE. The AnovCTE cows had decreased P/AI at PD2 compared with CycHealthy cows (12.5 vs. $54.1 \% ; P=0.05)$, whereas AnovHealthy $(43.6 \% ; P=0.22)$ and CycCTE cows $(40.4 \% ; P=0.08)$ had intermediate $\mathrm{P} / \mathrm{AI}$. In the combined data sets 2 and 3, an effect of $\operatorname{VarCycCTE}(P<0.001)$ was de-

Table 1. Results from the multivariable mixed logistic regression model having pregnancy per AI (P/AI) at first pregnancy diagnosis performed between 30 and $41 \mathrm{~d}$ after first $\mathrm{AI}$ in data sets 1,2 , and 3 as the outcome variable ${ }^{1,2}$

\begin{tabular}{|c|c|c|c|c|c|c|c|c|c|c|c|c|}
\hline Variable $^{3}$ & \multicolumn{4}{|c|}{ Data set 1} & \multicolumn{4}{|c|}{ Data set 2} & \multicolumn{4}{|c|}{ Data set 3} \\
\hline AnovCTE & 34 & 20.6 & 0.60 & 0.26 & 108 & 22.2 & 0.45 & 0.003 & 8 & 12.5 & 0.09 & 0.03 \\
\hline СycCTE & 118 & 27.1 & 0.80 & 0.39 & 174 & 38.5 & 0.87 & 0.45 & 47 & 48.9 & 0.62 & 0.13 \\
\hline CycHealthy & 205 & 32.7 & - & - & 355 & 42.3 & - & - & 322 & 60.6 & - & - \\
\hline
\end{tabular}

${ }^{1}$ Odds ratios $(\mathrm{OR})$ and $P$-values were adjusted for any significant effect of the fixed variables calving season (winter, spring, summer, and fall), parity (primiparous or multiparous), BCS at 35 DIM $(\leq 2.75$ or $>2.75)$, and the respective treatment applied as part of the original study.

${ }^{2}$ Data set 1 = data collected from 403 Holstein cows from 5 commercial dairies located in upstate New York. Data set $2=$ data collected from 750 Holstein cows from 2 commercial dairies located in Northern Florida $(\mathrm{n}=429)$ and central California $(\mathrm{n}=321)$. Data set $3=$ data collected from 416 multiparous cows (165 Holsteins, 36 Jerseys, and 215 Holstein-Jersey crossbreeds) from one commercial dairy located in north-central Florida.

${ }^{3}$ Anov $=$ anovular; Cyc $=$ cyclic $;$ CTE $=$ presence of cytological endometritis; Healthy $=$ absence of CTE. 
Table 2. Results from the multivariable mixed logistic regression model having pregnancy per $\mathrm{AI}(\mathrm{P} / \mathrm{AI})$ at first pregnancy diagnosis performed between 30 and $41 \mathrm{~d}$ after first $\mathrm{AI}$ in the combined data set $^{1}$ as the outcome variable ${ }^{2}$

\begin{tabular}{lcccc}
\hline Variable $^{3}$ & No. & P/AI, \% & OR & $P$-value \\
\hline AnovCTE & 150 & 21.3 & 0.41 & $<0.001$ \\
AnovHealthy & 198 & 37.9 & 0.78 & 0.14 \\
CycCTE & 339 & 36.0 & 0.77 & 0.06 \\
CycHealthy & 882 & 46.7 & - & - \\
\hline
\end{tabular}

${ }^{1}$ Combined data set $=$ combination of data sets 1,2 , and 3 . Data set 1 = data collected from 403 Holstein cows from 5 commercial dairies located in upstate New York. Data set $2=$ data collected from 750 Holstein cows from 2 commercial dairies located in Northern Florida $(\mathrm{n}=429)$ and central California $(\mathrm{n}=321)$. Data set $3=$ data collected from 416 multiparous cows (165 Holsteins, 36 Jerseys, and 215 Holstein-Jersey crossbreeds) from one commercial dairy located in north-central Florida.

${ }^{2}$ Odds ratios (OR) and $P$-values were adjusted for any effect of herd (random variable) and any significant effect of the fixed variables calving season (winter, spring, summer, and fall), parity (primiparous or multiparous), BCS at 35 DIM $(\leq 2.75$ or $>2.75)$, and the respective treatment applied as part of the original study.

${ }^{3} \mathrm{Anov}=$ anovular; $\mathrm{Cyc}=$ cyclic CTE $=$ presence of cytological endometritis; Healthy $=$ absence of CTE.

tected, with results following a similar pattern to the individual data sets, and AnovCTE cows had decreased $\mathrm{P} / \mathrm{AI}$ at PD2 compared with CycHealthy cows (19.0 vs. $46.1 \% ; P<0.001)$, whereas AnovHealthy $(35.5 \% ; P=$ $0.08)$ and CycCTE cows $(34.8 \% ; P=0.03)$ had intermediate P/AI, but with AnovHealthy cows approaching significance and CycCTE cows being significantly different from CycHealthy cows.

Pregnancy losses from PD1 to PD2 for data sets 2 and 3 and for the combined data set are shown in Table 4. No effect $(P>0.20)$ of VarCycCTE on PL on the individual or combined data sets was detected.

The analyses of hazard of pregnancy up to 300 DIM in data sets 1 and 2, and for the combination of both data sets are shown in Table 5 . In data set 1 , an effect
$(P=0.02)$ of VarCycCTE was detected, with AnovCTE $(P=0.01)$ and AnovHealthy cows $(P=0.05)$ having decreased hazard of pregnancy compared with $\mathrm{Cy}$ cHealthy cows, and CycCTE cows having a tendency $(P=0.07)$ for decreased hazard of pregnancy compared with CycHealthy cows. Median days open were 180, 171, 159, and 122 for AnovCTE, AnovHealthy, CycCTE, and CycHealthy, respectively (Figure 1). In data set 2 , an effect $(P<0.001)$ of VarCycCTE was detected, with AnovCTE $(P<0.001)$ and AnovHealthy cows $(P=0.009)$ having decreased hazard of pregnancy compared with CycHealthy cows, and CycCTE cows having a tendency $(P=0.06)$ for decreased hazard of pregnancy compared with CycHealthy cows. Median days open were 203, 156, 140, and 121 for AnovCTE, AnovHealthy, CycCTE, and CycHealthy, respectively (Figure 2). In the combined data set, an effect $(P<$ 0.001) of VarCycCTE was detected, with AnovCTE $(P$ $<0.001)$, AnovHealthy $(P=0.001)$, and CycCTE cows $(P=0.008)$ having decreased hazard of pregnancy compared with CycHealthy cows. Median days open were 200, 159, 145, and 121 for AnovCTE, AnovHealthy, CycCTE, and CycHealthy cows, respectively (Figure 3).

\section{DISCUSSION}

This study was designed to evaluate the individual and combined effects of anovulation and CTE on reproductive performance of dairy cows; therefore, the effect of other covariates were not presented because they have been presented and discussed extensively in the original publications and in several other works (Galvão et al., 2009a; Santos et al., 2009; Ribeiro et al., 2013). Previous reports in confinement dairies showed that CTE impairs reproductive performance by delaying first service, reducing pregnancy to first postpartum AI, and increasing number of services per

Table 3. Results from the multivariable mixed logistic regression model having pregnancy per AI (P/AI) at the confirmation pregnancy diagnosis performed between 65 and $75 \mathrm{~d}$ after first AI in data sets 2 and 3 , and the combination of both data sets as the outcome variable ${ }^{1,2}$

\begin{tabular}{|c|c|c|c|c|c|c|c|c|c|c|c|c|}
\hline Variable $^{3}$ & \multicolumn{4}{|c|}{ Data set 2} & \multicolumn{4}{|c|}{ Data set 3} & \multicolumn{4}{|c|}{ Combined data set } \\
\hline AnovCTE & 108 & 19.4 & 0.41 & 0.001 & 8 & 12.5 & 0.12 & 0.05 & 116 & 19.0 & 0.35 & $<0.001$ \\
\hline CycCTE & 174 & 33.3 & 0.78 & 0.21 & 47 & 40.4 & 0.58 & 0.08 & 221 & 34.8 & 0.70 & 0.03 \\
\hline CycHealthy & 355 & 38.9 & - & - & $320^{4}$ & 54.1 & - & - & $675^{4}$ & 46.1 & - & - \\
\hline
\end{tabular}

${ }^{1}$ Odds ratios $(\mathrm{OR})$ and $P$-values were adjusted for any effect of herd (random variable in the combined data set) and any significant effect of the fixed variables calving season (winter, spring, summer, and fall), parity (primiparous or multiparous), BCS at 35 DIM ( $\leq 2.75$ or $>2.75$ ), and the respective treatment applied as part of the original study.

${ }^{2}$ Data set $2=$ data collected from 750 Holstein cows from two commercial dairies located in Northern Florida $(\mathrm{n}=429)$ and central California $(\mathrm{n}=321)$. Data set $3=$ data collected from 416 multiparous cows, 165 Holsteins, 36 Jerseys, and 215 Holstein-Jersey crossbreeds from one commercial dairy located in north-central Florida.

${ }^{3} \mathrm{Anov}=$ anovular; $\mathrm{Cyc}=$ cyclic CTE $=$ presence of cytological endometritis; Healthy $=$ absence of CTE.

${ }^{4}$ Two cows that were pregnant at pregnancy diagnosis 1 were sold or died before the reconfirmation pregnancy diagnosis. 
Table 4. Results from the multivariable mixed logistic regression model having pregnancy loss (PL) from the first pregnancy diagnosis performed between 30 and $41 \mathrm{~d}$ after AI to the second pregnancy diagnosis performed between 65 and $75 \mathrm{~d}$ after AI in data sets 2 and 3 , and for the combination of both data sets as the outcome variable ${ }^{1,2}$

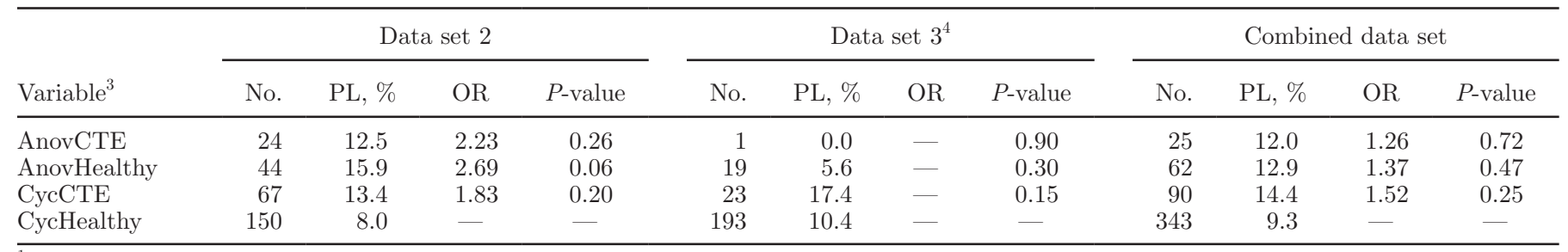

${ }^{1}$ Odds ratio $(\mathrm{OR})$ and $P$-values were adjusted for any effect of herd (random variable in the combined data set) and any significant effect of the fixed variables calving season (winter, spring, summer, and fall), parity (primiparous or multiparous), BCS at 35 DIM ( $\leq 2.75$ or $>2.75$ ), and the respective treatment applied as part of the original study.

${ }^{2}$ Data set $2=$ data collected from 750 Holstein cows from 2 commercial dairies located in Northern Florida $(\mathrm{n}=429)$ and central California $(\mathrm{n}$ =321). Data set 3 = data collected from 416 multiparous cows (165 Holsteins, 36 Jerseys, and 215 Holstein-Jersey crossbreeds) from one commercial dairy located in north-central Florida.

${ }^{3}$ Anov $=$ anovular; $\mathrm{Cyc}=$ cyclic CTE $=$ presence of cytological endometritis; Healthy $=$ absence of CTE.

${ }^{4}$ Because the AnovCTE group only had one cow and no PL, quasi-complete separation of data points occurred, which led to unreliable estimates; therefore, a Fisher exact test was used for multiple comparisons instead of a multivariable analysis.

conception and time to pregnancy (Kasimanickam et al. 2004; Gilbert et al., 2005). In pasture-based dairies, Madoz et al. (2013) reported that cows with CTE had a decreased hazard for pregnancy and increased calvingto-conception interval. Anovulation also impairs reproductive performance by delaying first service, reducing pregnancy to first AI, and increasing the number of AI per conception and time to pregnancy (Rhodes et al., 2003; Cerri et al., 2004; Galvão et al., 2004). In previous work, we observed that CTE and anovulation were associated (Galvão et al., 2010b). Others have also found an association between clinical endometritis and anovulation (Opsomer et al., 2000; Dubuc et al., 2012; Kadivar et al. 2014); therefore, possibly making the effect of one variable indistinguishable from the effect of the other. Nonetheless, the findings observed herein showed that both anovulation and CTE have a similar negative effect on reproductive performance, and they have an additive effect when combined. Of relevance is also the fact that this effect was observed in confinement dairies in 3 different regions of the country as well as in a grazing dairy, thereby increasing the external validity of our observations.

The association between endometritis and anovulation is, in part, explained by the fact that bacterial contamination of the uterus in early lactation and the associated inflammatory process may lead to a decrease in secretion of luteinizing hormone (Peter et al., 1989; Rivest et al., 1993; Battaglia et al., 1999), decreased first dominant follicle size and growth, and decreased follicular steroidogenesis (Sheldon et al., 2002; Williams et al., 2007; Williams et al., 2008), thereby affecting ovulatory capacity and delaying resumption of ovarian cyclicity (Opsomer et al., 2000; Kadivar et al. 2014). Another important factor that helps to explain the association between endometritis and anovulation is the fact that both are positively associated with the degree of negative energy balance early postpartum (Beam

Table 5. Results from the Cox proportional hazard model having time to pregnancy up to 300 DIM in data sets 1 and 2 , and for the combination of both data sets as the outcome variable ${ }^{1,2}$

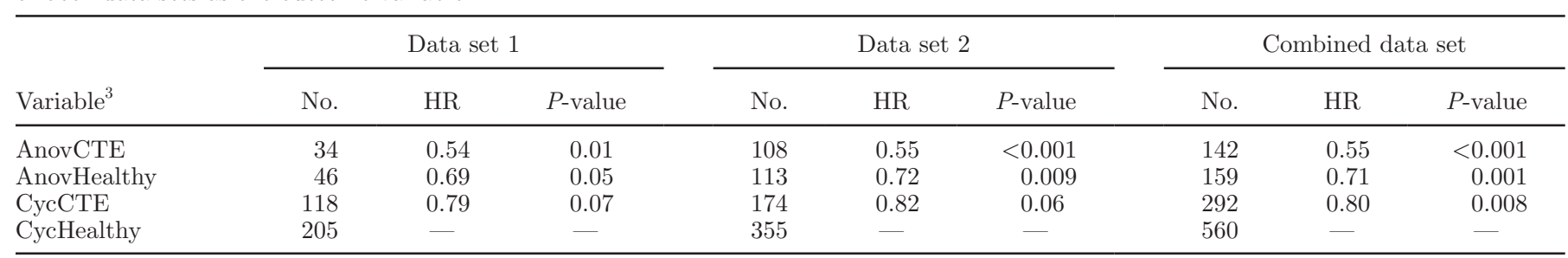

${ }^{1}$ Hazard ratio (HR) and $P$-values were adjusted for any effect of herd (added a stratum in the combined data set) and any significant effect of the fixed variables calving season (winter, spring, summer, and fall), parity (primiparous or multiparous), BCS at 35 DIM ( $\leq 2.75$ or $>2.75$ ), and the respective treatment applied as part of the original study.

${ }^{2}$ Data set 1 = data collected from 403 Holstein cows from 5 commercial dairies located in upstate New York. Data set $2=$ data collected from 750 Holstein cows from 2 commercial dairies located in Northern Florida $(\mathrm{n}=429)$ and central California $(\mathrm{n}=321)$. Data set $3=$ data collected from 416 multiparous cows (165 Holsteins, 36 Jerseys, and 215 Holstein-Jersey crossbreeds) from one commercial dairy located in north-central Florida.

${ }^{3}$ Anov $=$ anovular Cyc $=$ cyclic; $\mathrm{CTE}=$ presence of cytological endometritis; Healthy $=$ absence of CTE. 


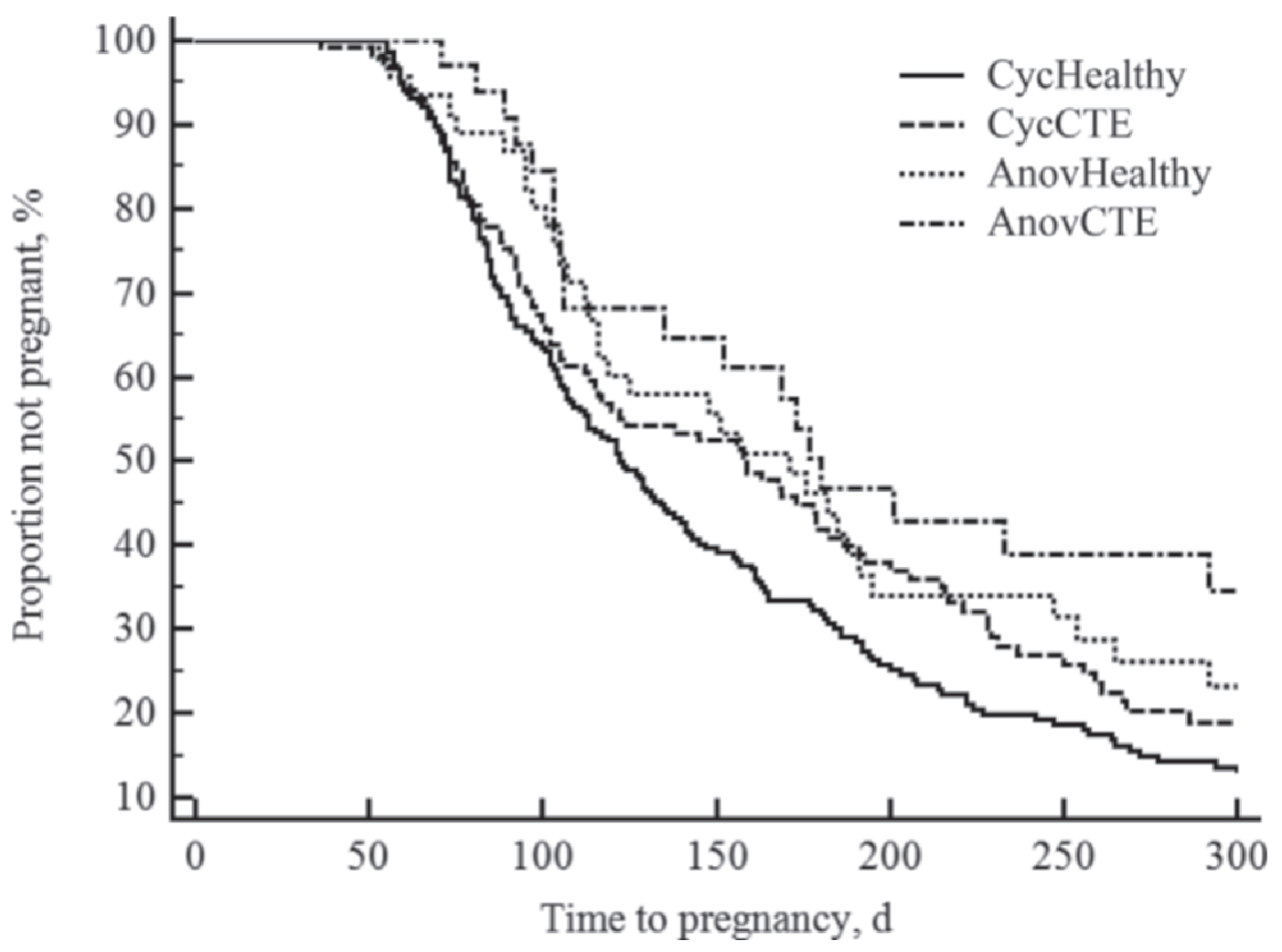

Figure 1. Kaplan-Meier survival curves for time to pregnancy up to 300 DIM according to cyclic status $($ cyclic $=$ Cyc; anovular $=$ Anov $)$ and the presence of cytological endometritis (present $=\mathrm{CTE}$; absent $=$ Healthy) in data set 1 . Data set $1=$ data collected from 403 Holstein cows from 5 commercial dairies located in upstate New York. Median days open were 122 for CycHealthy $(\mathrm{n}=205), 159$ for CycCTE $(\mathrm{n}=118), 171$ for AnovHealthy $(\mathrm{n}=46)$, and 180 for AnovCTE $(\mathrm{n}=34)$.

and Butler, 1999; Hammon et al., 2006; Galvão et al., 2010a). Therefore, at least one of the negative effects of CTE on reproductive performance, namely the increased time to first service when $\mathrm{AI}$ is based on estrus detection (Gilbert et al., 2005), is probably the result of the association between CTE and anovulation. Nonetheless, as was observed herein, CTE affects P/AI and time to pregnancy even in cyclic cows and, similarly, anovulation affects $\mathrm{P} / \mathrm{AI}$ and time to pregnancy even in cows without CTE.

The individual negative effects of CTE are probably mediated by direct effects of inflammation in the uterus and ovary. The inflammatory process associated with uterine diseases is characterized by massive migration of PMNL to the surface epithelium and into the lumen of the endometrial glands and the surrounding tissue. This increase infiltration of immune cells results in occlusion of the endometrial glands, dilation of underlying glands with deposit of connective tissue, and formation of scar tissue in the uterus (McEntee, 1990; Bonnett et al., 1991; Sheldon and Dobson, 2004), which may affect embryonic implantation and maintenance of pregnancy. Furthermore, evidence exists that inflammation also directly impairs embryo development (Soto et al., 2003;
Hill and Gilbert, 2008; Hoelker et al., 2012). In addition, activation of the inflammatory cascade may either stimulate the release of $\mathrm{PGF}_{2 \alpha}$ from the endometrium (Skarzynski et al., 2005; Kaneko and Kawakami, 2009; Kaneko et al., 2013), hence inducing luteolysis or even extending luteal lifespan (Mateus et al., 2002; Skarzynski et al., 2005; Herath et al., 2009), which can decrease $\mathrm{P} / \mathrm{AI}$ or increase reinsemination interval and time to pregnancy (Opsomer et al., 2000; Ranasinghe et al., 2011), respectively.

The individual negative effects of anovulation on reproductive performance are probably a result of increased time to first service when AI is based on detected estrus and decreased P/AI because of negative effects on the uterus, oocyte, and embryo development. Low concentrations of progesterone during the growth of the ovulatory follicle have been found to affect uterine endometrial morphology (Shaham-Albalancy et al., 1997), which is thought to affect endometrial secretory function during early gestation and also to increase the synthesis of $\mathrm{PGF}_{2 \alpha}$ in response to oxytocin (ShahamAlbalancy et al., 2001), which may affect embryo development and lead to premature luteolysis (Garverick et al., 1992; Cerri et al., 2011a), respectively. Further- 


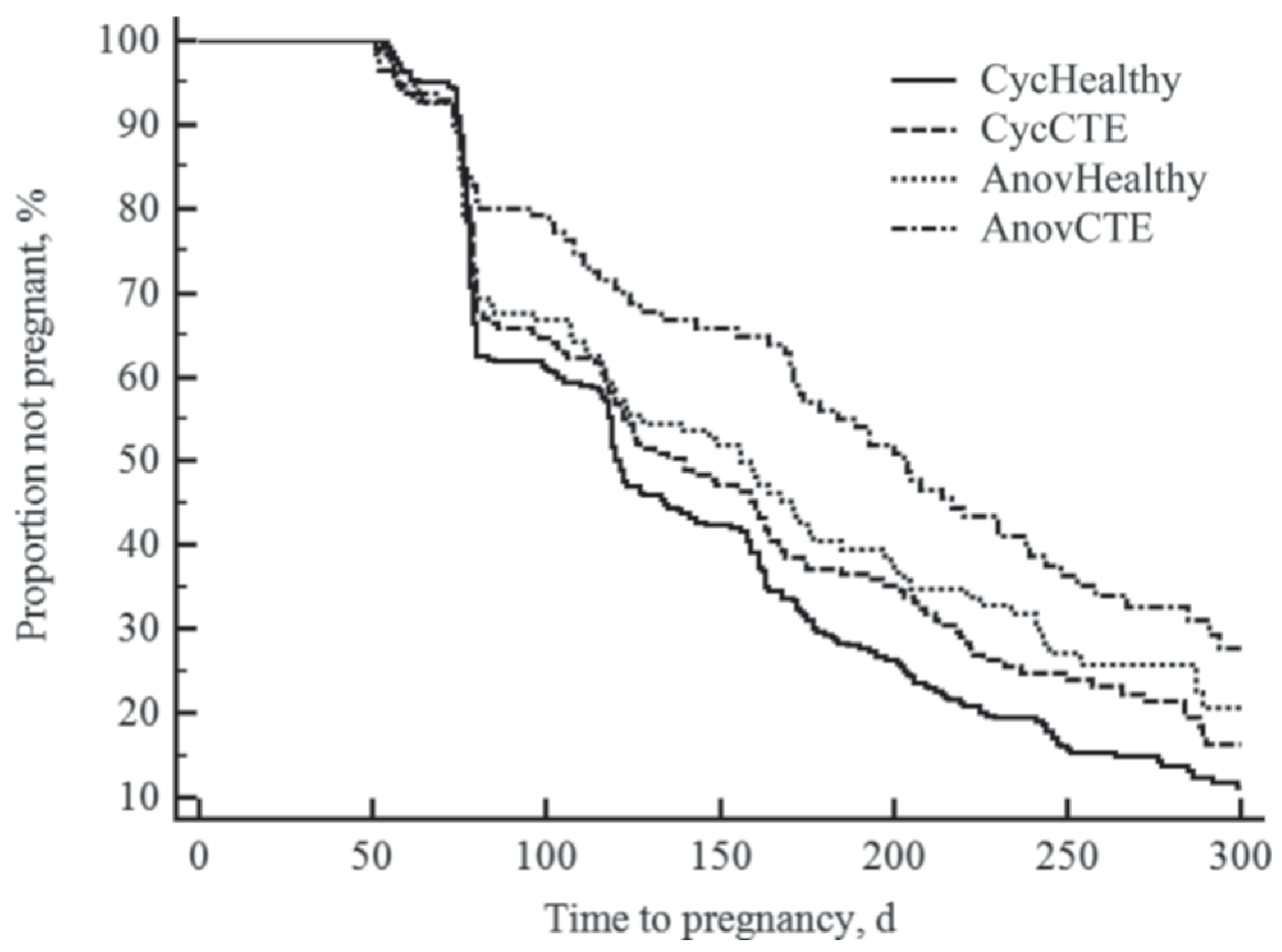

Figure 2. Kaplan-Meier survival curves for time to pregnancy up to 300 DIM according to cyclic status (cyclic $=$ Cyc; anovular $=$ Anov) and the presence of cytological endometritis (present $=$ CTE; absent $=$ Healthy) in data set 2 . Data set $2=$ data collected from 750 Holstein cows from 2 commercial dairies located in Northern Florida $(\mathrm{n}=429)$ and central California $(\mathrm{n}=321)$. Median days open were 121 for CycHealthy $(\mathrm{n}=355), 140$ for CycCTE $(\mathrm{n}=174), 156$ for AnovHealthy $(\mathrm{n}=113)$, and 203 for AnovCTE $(\mathrm{n}=108)$.

more, low concentrations of progesterone during the growth of the ovulatory follicle have been associated with greater LH concentrations, faster growth of the ovulatory follicle, lower intrafollicular IGF-1 concentration, and compromised embryo quality (Cerri et al., 2011a,b; Rivera et al., 2011).

As expected, when cows had both conditions, namely anovulation and CTE, the negative effect on reproductive performance was compounded and an almost perfect additive effect, with doubling of the negative effect, was observed on the odds and hazard of pregnancy. The only exception was the lack of a significant individual or combined effect of anovulation or CTE on PL; only a tendency was observed for increased PL for AnovHealthy cows in data set 2. Although a clear numerical increase occurred in PL when cows were anovular or had CTE, no clear trend indicating an additive effect was observed. Both anovulation (Santos et al., 2004) and CTE (Lima et al., 2013) have been found to negatively affect maintenance of pregnancy in dairy cows. Nonetheless, the effect of anovulation on PL has not been consistent (Santos et al., 2009) and only a few studies exist that evaluated the effect of CTE on PL (Galvão et al., 2009b; Lima et al., 2013); therefore, further studies are needed to clarify the effect of anovulation and CTE on PL. An important point to consider for future studies is the standardization of sampling times. Although we tried to correct for different sampling times for CTE by using different PMNL thresholds, the same could not be done for anovulation. Different sampling times would affect the prevalence of anovulation (Galvão et al., 2010b; Dubuc et al., 2012) and could potentially affect the magnitude of the observed differences.

It is important to point out that the study results may have been affected by sampling bias because the animals used were sampled from previous studies and not randomly selected from the population. Also, because this was a convenience sample from previous studies, the analyses for P/AI to the first service were somewhat underpowered (i.e., only showed tendencies for the AnovHealthy and CycCTE groups). Nonetheless, this study provides expected differences among the 4 groups for P/AI to first service for future experiments. Furthermore, the study provides a target for an appropriate sample size to evaluate time to pregnancy. Therefore, prospective studies using randomly selected animals are needed to confirm our findings. 


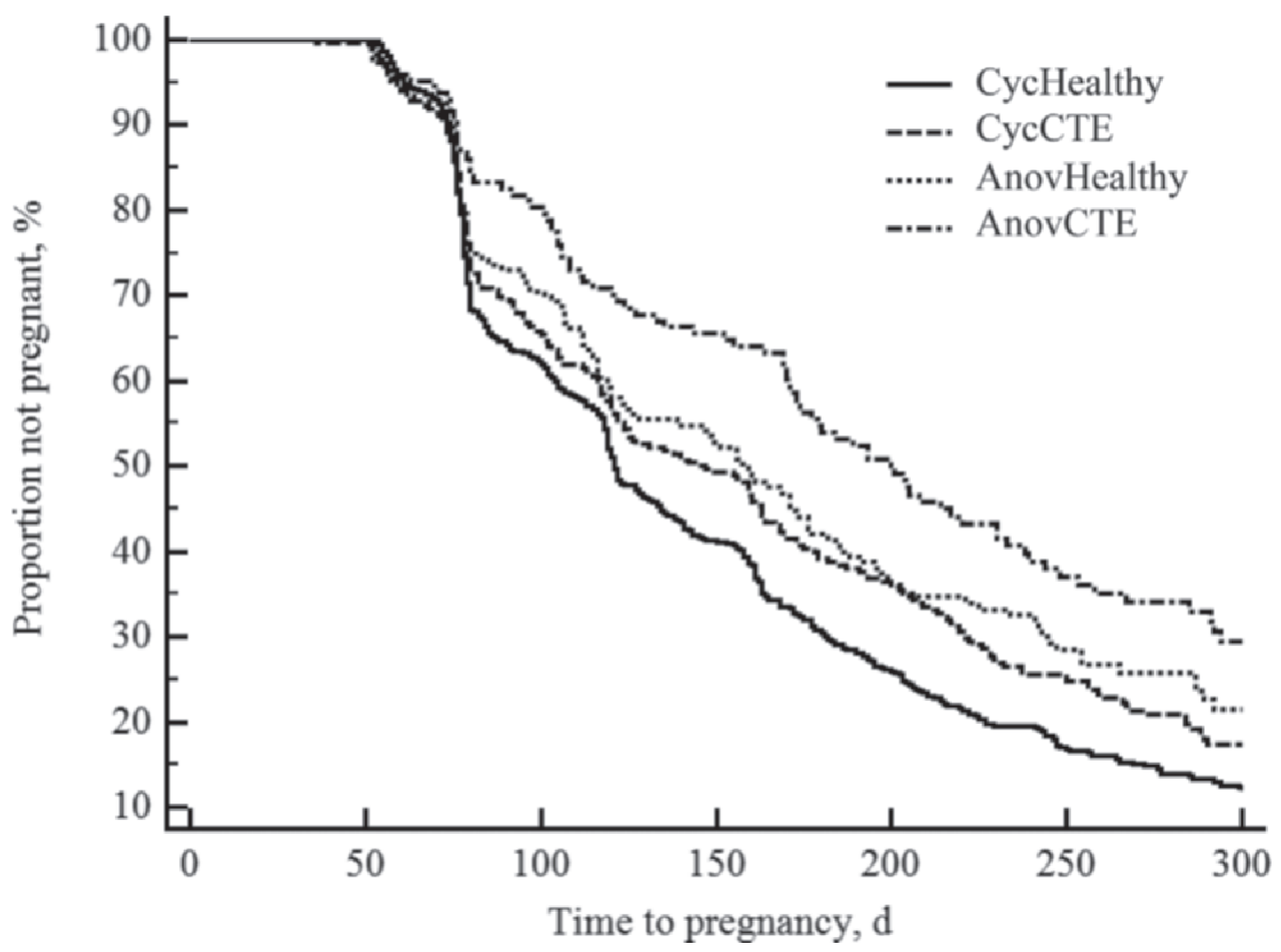

Figure 3. Kaplan-Meier survival curves for time to pregnancy up to 300 DIM according to cyclic status (cyclic = Cyc; anovular = Anov) and the presence of cytological endometritis (present $=\mathrm{CTE}$; absent $=$ Healthy) in the combined data set (data sets 1 and 2$)$. Data set $1=$ data collected from 403 Holstein cows from 5 commercial dairies located in upstate New York. Data set $2=$ data collected from 750 Holstein cows from 2 commercial dairies located in Northern Florida $(\mathrm{n}=429)$ and central California $(\mathrm{n}=321)$. Median days open were 121 for CycHealthy $(\mathrm{n}=560), 145$ for CycCTE $(\mathrm{n}=292), 159$ for AnovHealthy $(\mathrm{n}=159)$, and 200 for AnovCTE $(\mathrm{n}=142)$.

\section{CONCLUSIONS}

Both anovulation and CTE negatively affected reproductive performance, especially $\mathrm{P} / \mathrm{AI}$ and time to pregnancy. Furthermore, when combined, anovulation and CTE had an additive negative effect. This trend was observed in all data sets, regardless of region of the country, reproductive management, or housing type. Prospective studies are needed to confirm our findings and to further evaluate the effect of anovulation and CTE on PL.

\section{ACKNOWLEDGMENTS}

The authors thank the owners and staff or the collaborating dairies and the Science Without Borders Program from the Brazilian National Council for Scientific and Technological Development (CNPq-Brazil, Brasília, Brazil) for providing a 1-yr scholarship to A. Vieira-Neto.

\section{REFERENCES}

Barlund, C. S., T. D. Carruthers, C. L. Waldner, and C. W. Palmer. 2008. A comparison of diagnostic techniques for postpartum endometritis in dairy cattle. Theriogenology 69:714-723.
Battaglia, D. F., A. B. Beaver, T. G. Harris, E. Tanhehco, C. Viguie, and F. J. Karsch. 1999. Endotoxin disrupts the estradiol-induced luteinizing hormone surge: Interference with estradiol signal reading, not surge release. Endocrinology 140:2471-2479.

Beam, S. W., and W. R. Butler. 1999. Effects of energy balance on follicular development and first ovulation in postpartum dairy cows. J. Reprod. Fertil. Suppl. 54:411-424.

Bittar, J. H., P. Pinedo, K. E. Hencken, C. C. Barbosa, M. Gobikrushanth, S. Croyle, C. A. Risco, A. Vieira-Neto, J. E. Santos, and K. N. Galvão. 2013. Effects of induction of ovulation, early in lactation, on uterine health and fertility in dairy cows. J. Dairy Sci. 96(E. Suppl. 1):118-119. (Abstr.)

Bonnett, B. N., S. W. Martin, V. P. J. Gannon, R. B. Miller, and W. G. Etherington. 1991. Endometrial biopsy in Holstein-Friesian dairy cows. III. Bacterial analysis and correlations with histological findings. Can. J. Vet. Res. 55:168-173.

Bruno, R. G., M. F. Sá Filho, D. F. Resende, F. S. Lima, and J. E. P. Santos. 2007. The effect of uterine infusion of ceftiofur in the immediate postpartum on uterine health in dairy cows. J. Dairy Sci. 90(Suppl. 1):10. (Abstr.)

Cerri, R. L., R. C. Chebel, F. Rivera, C. D. Narciso, R. A. Oliveira, M. Amstalden, G. M. Baez-Sandoval, L. J. Oliveira, W. W. Thatcher, and J. E. P. Santos. 2011a. Concentration of progesterone during the development of the ovulatory follicle: II. Ovarian and uterine responses. J. Dairy Sci. 94:3352-3365.

Cerri, R. L., R. C. Chebel, F. Rivera, C. D. Narciso, R. A. Oliveira, W. W. Thatcher, and J. E. P. Santos. 2011b. Concentration of progesterone during the development of the ovulatory follicle: I. Ovarian and embryonic responses. J. Dairy Sci. 94:3342-3351.

Cerri, R. L., J. E. Santos, S. O. Juchem, K. N. Galvão, and R. C. Chebel. 2004. Timed artificial insemination with estradiol cypi- 
onate or insemination at estrus in high-producing dairy cows. J. Dairy Sci. 87:3704-3715.

Chebel, R. C., J. E. P. Santos, R. L. Cerri, H. M. Rutigliano, and R. G. Bruno. 2006. Reproduction in dairy cows following progesterone insert presynchronization and resynchronization protocols. J. Dairy Sci. 89:4205-4219.

Cheong, S. H., D. V. Nydam, K. N. Galvão, B. M. Crosier, and R. O. Gilbert. 2011. Cow-level and herd-level risk factors for subclinical endometritis in lactating Holstein cows. J. Dairy Sci. 94:762-770.

Darwash, A. O., G. E. Lamming, and J. A. Woolliams. 1997. The phenotypic association between the interval to postpartum ovulation and traditional measures of fertility in dairy cattle. Anim. Sci. 65:9-16.

Dubuc, J., T. F. Duffield, K. E. Leslie, J. S. Walton, and S. J. LeBlanc. 2012. Risk factors and effects of postpartum anovulation in dairy cows. J. Dairy Sci. 95:1845-1854. http://dx.doi.org/10.3168/ jds.2011-4781.

Dubuc, J., T. F. Duffield, K. E. Leslie, J. S. Walton, and S. J. LeBlanc. 2010. Definitions and diagnosis of postpartum endometritis in dairy cows. J. Dairy Sci. 93:5225-5233.

El-Zarkouny, S. Z., J. A. Cartmill, B. A. Hensley, and J. S. Stevenson. 2004. Pregnancy in dairy cows after synchronized ovulation regimens with or without presynchronization and progesterone. J. Dairy Sci. 87:1024-1037.

Ferguson, J. D., D. T. Galligan, and N. Thomsen. 1994. Principal descriptors of body condition score in Holstein cows. J. Dairy Sci. 77:2695-2703.

Galvão, K. N., M. J. Flaminio, S. B. Brittin, R. Sper, M. Fraga, L. Caixeta, A. Ricci, C. L. Guard, W. R. Butler, and R. O. Gilbert. 2010a. Association between uterine disease and indicators of neutrophil and systemic energy status in lactating Holstein cows. J. Dairy Sci. 93:2926-2937.

Galvão, K. N., M. Frajblat, S. B. Brittin, W. R. Butler, C. L. Guard, and R. O. Gilbert. 2009a. Effect of $\mathrm{PGF}_{2 \alpha}$ on subclinical endometritis and fertility in dairy cows. J. Dairy Sci. 92:4906-4913.

Galvão, K. N., M. Frajblat, W. R. Butler, S. B. Brittin, C. L. Guard, and R. O. Gilbert. 2010b. Effect of early postpartum ovulation on fertility in dairy cows. Reprod. Domest. Anim. 45:e207-e211.

Galvão, K. N., L. F. Greco, J. M. Vilela, M. F. Sá Filho, and J. E. P. Santos. 2009b. Effect of intrauterine infusion of ceftiofur on uterine health and fertility in dairy cows. J. Dairy Sci. 92:1532-1542.

Galvão, K. N., J. E. Santos, S. O. Juchem, R. L. Cerri, A. C. Coscioni, and M. Villasenor. 2004. Effect of addition of progesterone intravaginal insert to a timed insemination protocol using estradiol cypionate on ovulation rate, pregnancy rate, and late embryonic loss in lactating dairy cows. J. Anim. Sci. 82:3508-3517.

Garverick, H. A., W. G. Zollers Jr., and M. F. Smith. 1992. Mechanisms associated with corpus luteum lifespan in animals having normal or subnormal luteal function. Anim. Reprod. Sci. 28:111124.

Gilbert, R. O., S. T. Shin, C. L. Guard, H. N. Erb, and M. Frajblat. 2005. Prevalence of endometritis and its effects on reproductive performance of dairy cows. Theriogenology 64:1879-1888.

Hammon, D. S., I. M. Evjen, T. R. Dhiman, J. P. Goff, and J. L. Walters. 2006. Neutrophil function and energy status in Holstein cows with uterine health disorders. Vet. Immunol. Immunopathol. 113:21-29.

Herath, S., S. T. Lilly, D. P. Fischer, E. J. Williams, H. Dobson, C. E. Bryant, and I. M. Sheldon. 2009. Bacterial lipopolysaccharide induces an endocrine switch from prostaglandin $\mathrm{F}_{2 \alpha}$ to prostaglandin $\mathrm{E}_{2}$ in bovine endometrium. Endocrinology 150:1912-1920.

Hill, J., and R. Gilbert. 2008. Reduced quality of bovine embryos cultured in media conditioned by exposure to an inflamed endometrium. Aust. Vet. J. 86:312-316.

Hoelker, M., D. Salilew-Wondim, M. Drillich, G. B. Christine, N. Ghanem, L. Goetze, D. Tesfaye, K. Schellander, and W. Heuwieser. 2012. Transcriptional response of the bovine endometrium and embryo to endometrial polymorphonuclear neutrophil infiltration as an indicator of subclinical inflammation of the uterine environment. Reprod. Fertil. Dev. 24:778-793.
Kadivar, A., M. R. Ahmadi, and M. Vatankhah. 2014. Associations of prepartum body condition score with occurrence of clinical endometritis and resumption of postpartum ovarian activity in dairy cattle. Trop. Anim. Health Prod. 46:121-126. http://dx.doi. org/10.1007/s11250-013-0461-9.

Kaneko, K., and S. Kawakami. 2009. The roles of $\mathrm{PGF}_{2 \alpha}$ and $\mathrm{PGE}_{2}$ in regression of the corpus luteum after intrauterine infusion of Arcanobacterium pyogenes in cows. Theriogenology 71:858-863.

Kaneko, K., M. Nakamura, and R. Sato. 2013. Influence of Trueperella pyogenes in uterus on corpus luteum lifespan in cycling cows. Theriogenology 79:803-808.

Kasimanickam, R., T. F. Duffield, R. A. Foster, C. J. Gartley, K. E. Leslie, J. S. Walton, and W. H. Johnson. 2004. Endometrial cytology and ultrasonography for the detection of subclinical endometritis in postpartum dairy cows. Theriogenology 62:9-23.

Lima, F. S., R. S. Bisinotto, E. S. Ribeiro, L. F. Greco, H. Ayres, M. G. Favoreto, M. R. Carvalho, K. N. Galvão, and J. E. Santos. 2013 Effects of 1 or 2 treatments with prostaglandin $\mathrm{F}_{2 \alpha}$ on subclinical endometritis and fertility in lactating dairy cows inseminated by timed artificial insemination. J. Dairy Sci. 96:6480-6488.

Madoz, L. V., M. J. Giuliodori, M. Jaureguiberry, J. Plöntzke, M. Drillich, and R. L. de la Sota. 2013. The relationship between endometrial cytology during estrous cycle and cutoff points for the diagnosis of subclinical endometritis in grazing dairy cows. J. Dairy Sci. 96:4333-4339.

Mateus, L., L. L. da Costa, F. Bernardo, and J. R. Silva Jr. 2002. Influence of puerperal uterine infection on uterine involution and postpartum ovarian activity in dairy cows. Reprod. Domest. Anim. 37:31-35.

McArt, J. A., L. S. Caixeta, V. S. Machado, C. L. Guard, K. N Galvão, O. G. Sá Filho, and R. C. Bicalho. 2010. Ovsynch versus Ultrasynch: Reproductive efficacy of a dairy cattle synchronization protocol incorporating corpus luteum function. J. Dairy Sci. 93:2525-2532.

McEntee, K. 1990. Reproductive Pathology of Domestic Animals. Academic Press Inc., San Diego, CA.

NRC. 2001. Nutrient Requirements of Dairy Cattle. 7th rev. ed., Natl. Acad. Sci., Washington, DC.

Opsomer, G., Y. T. Gröhn, J. Hertl, M. Coryn, H. Deluyker, and A. de Kruif. 2000. Risk factors for post partum ovarian dysfunction in high producing dairy cows in Belgium: A field study. Theriogenology $53: 841-857$.

Peter, A. T., W. T. Bosu, and R. J. DeDecker. 1989. Suppression of preovulatory luteinizing hormone surges in heifers after intrauterine infusions of Escherichia coli endotoxin. Am. J. Vet. Res. $50: 368-373$.

Ranasinghe, R. M., T. Nakao, K. Yamada, K. Koike, A. Hayashi, and C. M. Dematawewa. 2011. Characteristics of prolonged luteal phase identified by milk progesterone concentrations and its effects on reproductive performance in Holstein cows. J. Dairy Sci. 94:116-127.

Rhodes, F. M., S. McDougall, C. R. Burke, G. A. Verkerk, and K. L. Macmillan. 2003. Invited review: Treatment of cows with an extended postpartum anestrous interval. J. Dairy Sci. 86:1876-1894.

Ribeiro, E. S., F. S. Lima, L. F. Greco, R. S. Bisinotto, A. P. Monteiro, M. Favoreto, H. Ayres, R. S. Marsola, N. Martinez, W. W. Thatcher, and J. E. P. Santos. 2013. Prevalence of periparturient disease and effects on fertility of seasonally calving grazing dairy cows supplemented with concentrates. J. Dairy Sci. 96:5682-5697.

Rivera, F. A., L. G. Mendonça, G. Lopes Jr., J. E. P. Santos, R. V. Perez, M. Amstalden, A. Correa-Calderón, and R. C. Chebel. 2011. Reduced progesterone concentration during growth of the first follicular wave affects embryo quality but has no effect on embryo survival post transfer in lactating dairy cows. Reproduction 141:333-342.

Rivest, S., S. Lee, B. Attardi, and C. Rivier. 1993. The chronic intracerebroventricular infusion of interleukin- 1 beta alters the activity of the hypothalamic-pituitary-gonadal axis of cycling rats. I. Effect on LHRH and gonadotropin biosynthesis and secretion. Endocrinology 133:2424-2430. 
Santos, J. E. P., H. M. Rutigliano, and M. F. Sá Filho. 2009. Risk factors for resumption of postpartum estrous cycles and embryonic survival in lactating dairy cows. Anim. Reprod. Sci. 110:207-221.

Santos, J. E. P., W. W. Thatcher, R. C. Chebel, R. L. Cerri, and K. N. Galvão. 2004. The effect of embryonic death rates in cattle on the efficacy of estrus synchronization programs. Anim. Reprod. Sci. 82-83:513-535.

Shaham-Albalancy, A., Y. Folman, M. Kaim, M. Rosenberg, and D. Wolfenson. 2001. Delayed effect of low progesterone concentrations on bovine uterine $\mathrm{PGF}_{2 \alpha}$ secretion in the subsequent estrous cycle. Reproduction 122:643-648.

Shaham-Albalancy, A., A. Nyska, M. Kaim, M. M. Rosenberg, Y. Folman, and D. Wolfenson. 1997. Delayed effect of progesterone on endometrial morphology in dairy cows. Anim. Reprod. Sci. 48:159-174.

Sheldon, I. M., and H. Dobson. 2004. Postpartum uterine health in cattle. Anim. Reprod. Sci. 82-83:295-306.

Sheldon, I. M., G. S. Lewis, S. LeBlanc, and R. O. Gilbert. 2006 Defining postpartum uterine disease in cattle. Theriogenology 65:1516-1530.

Sheldon, I. M., D. E. Noakes, A. N. Rycroft, D. U. Pfeiffer, and H. Dobson. 2002. Influence of uterine bacterial contamination af- ter parturition on ovarian dominant follicle selection and follicle growth and function in cattle. Reproduction 123:837-845.

Skarzynski, D. J., J. J. Jaroszewski, and K. Okuda. 2005. Role of tumor necrosis factor- $\alpha$ and nitric oxide in luteolysis in cattle. Domest. Anim. Endocrinol. 29:340-346.

Soto, P., R. P. Natzke, and P. J. Hansen. 2003. Actions of tumor necrosis factor- $\alpha$ on oocyte maturation and embryonic development in cattle. Am. J. Reprod. Immunol. 50:380-388.

Walsh, R. B., D. F. Kelton, T. F. Duffield, K. E. Leslie, J. S. Walton, and S. J. LeBlanc. 2007. Prevalence and risk factors for postpartum anovulatory condition in dairy cows. J. Dairy Sci. 90:315-324.

Williams, E. J., D. P. Fischer, D. E. Noakes, G. C. W. England, A. Rycroft, H. Dobson, and I. M. Sheldon. 2007. The relationship between uterine pathogen growth density and ovarian function in the postpartum dairy cow. Theriogenology 68:549-559.

Williams, E. J., K. Sibley, A. N. Miller, E. A. Lane, J. Fishwick, D. M. Nash, S. Herath, G. C. England, H. Dobson, and I. M. Sheldon. 2008. The effect of Escherichia coli lipopolysaccharide and tumour necrosis factor alpha on ovarian function. Am. J. Reprod. Immunol. 60:462-473. 